\title{
TRANSITION FROM FALSE DOCTRINES TO PERFECT SCIENTIFIC KNOWLEDGE IS NATURAL DEVELOPMENT PROCESS OF INFORMATION SOCIETY
}

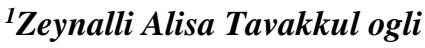 \\ PhD, Associate Professor, \\ Independent Researcher, Baku, Republic of Azerbaijan, \\ ${ }^{2}$ Zeynalov Sholat Alovsat oqli, \\ PhD on Philosophy, Senior Resercher, \\ Institute of Philosophy of National Academy of Sciences of Azerbaijan (NASA), \\ Baku, Republic of Azerbaijan, \\ ${ }^{3}$ Tapdiqli Guler Mohteber \\ Leading specialist, \\ Agro Research Center Under the Ministry of Agriculture of Azerbaijan, \\ Baku, Republic of Azerbaijan.
}

\section{ПЕРЕХОД ОТ ЛЖЕУЧЕНИЯ К СОВЕРШЕННОМУ НАУЧНОМУ ПОЗНАНИЮ ЗАКОНОМЕРНЫЙ ПРОЦЕСС РАЗВИТИЯ ИНФОРМАЦИОННОГО ОБЩЕСТВА}

\author{
DOI: $10.31618 /$ ESU.2413-9335.2019.5.62.156 \\ 1зейналль Алиса Таваккуль оглы \\ кандидат экономических наук, доцент,независимыій исследователь, \\ 2. Баку, Азербайджанская Республика; \\ 2 Зейналов Шолат Аловсат огль \\ доктор философии по философии, старший научный сотрудник, \\ Институт Философии Наџиональной Академии Наук Азербайджана (НАНА), \\ г. Баку Азербайджанская Республика; \\ ${ }^{3}$ Тапдыглы Гюляр Мохтабар кызы \\ ведущий специалист, Центр Аграрных Исследований при Министерстве \\ Сельского Хозяйства Азербайджана, г. Баку, Азербайджанская Республика.
}

\begin{abstract}
.
Main objective for writing of this article is consists in giving the certain offer on perfection the intellectual capital of society, its young generation. Considering undesirable, destructive tendencies of development in separate regions of the world, authors expresses the concern, tries to specify the reasons and to give offers for their prevention. Authors are proving the necessity of interrelation of religion and science for formation of knowledge and ability of modern person, for supplying with efficiency of economic relations and increasing its productivity and creating of stabilization in society.

\section{АННОТАЦИЯ.}

Основная цель написания этой статьи состоит в том, чтобы дать определенное предложение по совершенствованию интеллектуального капитала общества, его молодого поколения. Учитывая нежелательные, разрушительные тенденции развития в отдельных регионах мира, авторы выражают свою обеспокоенность, стараются уточнить причины и дать предложения по их предотвращению. Авторы обосновывают необходимость взаимосвязи религии и науки для формирования знаний и способностей современного человека, для обеспечения эффективности экономических отношений, повышения их продуктивности и создания стабилизации в обществе.

Keywords: good deed, spiritual and material worlds, development, science is the result of religion; religion is the power of integrating the development of society, means of supporting state stabilization.

Ключевые слова: доброе дело, духовный и материальный мир, развитие, наука результат религии, религия - сила интеграции развития общества, средства поддержки государственной стабилизации.

\section{1. Знание как важное средство интеллектуаль- ного развития человека}

По мнению исламистов, семь тысяч лет до создания Адама и Евы на планете Земля существовали (проживали) роды джинов и шимпанзе («наснасы»). Род шимпанзе был человекообразным существом, но он имел не две ноги, как у человека, а был одноногими, владел рассудком и был сознательным (видимо, эта действительность была воспринята со стороны Дарвина и его предшественников как источник формирования человеческого рода). Несмотря на то, что Бог велел им определен-

ный порядок проживания, они предпочли заниматься только злыми деяниями. Это не понравилось ангелам, и они просили Бога об их наказании. Бог посылал ангелов на Землю во главе дьявола (caтаны, демона) и известил их о своём собственном намерении: «О создании на Земле своего наместника (халифы)». После того как на Земной планете, приготовленной из раствора глины и воды было формировано тело Адама, Бог надувал из своего духовного сокровища и дал ему жизнь. Затем Он велел ангелам покланяться Адаму, его любимому созданию и наместнику. Все ангелы приняли этот наказ, кроме дьявола. Дьявол аргументировал свой
\end{abstract}


отказ тем что, он сам создан от огня, а особа (персона, натура, сущность) Адама исходит из земли, как он может покланяться нижестоящему существу. Поэтому Бог наказал дьявола, выгнал его с небесного местопребывания и послал для земной жизни до Судного дня. С тех пор человек и дьявол в непримиримом противоречии, второй старается обманывать первого, сбить его с правильного, доброго пути и заставляет заниматься злыми деяниями. Идет настоящая конкуренция [6, стр.9-12]. Слабые люди поддаются, а сильные проклинают его.

В одном из источников нам известно, что при смерти пророк Исмаил, старший сын Ибрагима завешал своему младшему брату - Исааку о женитьбе его дочери со своим сыном Ийсу [5, стр.172]. Из другого источника доходит информация о том, что у пророка Исаака были двойняшки - сыновья Якуб и Исав. Исав женился на дочери Исмаила. От них произошли множество поколений, они создали большое государство, охватив всю территорию Шама (часть территории нынешней Сирии). [7, стр.10]. В таких ситуациях кто точно может сказать, что сами пророки Ибрагим, Исмаил, Исаак, а также Исав и дети из его рода к какой нации себя относили?

Мусульманский мир, его духовные и материальные базисы основываются на религии Ислама, исламских рассуждений, науки, идей, знании, культуры. Мировоззрение исламистов во всех ее аспектах, в том числе, о происхождении человека, без сомнения, формировались согласно нормам Ислама. Поэтому каждый мусульманин глубоко убежден своему происхождению и считает своё начало от Адама и Евы. Для примера, полностью имя Мухаммеда выглядит так: Абуль-Касим Мухаммад ибн Абдуллах ибн Абд аль-Мутталиб (Шейба) ибн Хашим (Амр) ибн Абд Манаф (аль-Мугира) ибн Кусай ибн Килаб ибн Мурра ибн Кааб ибн Луай ибн Галиб ибн Фихр ибн Малик ибн ан-Надр ибн Кинана ибн Хузайма ибн Мудрик (Амир) ибн Ильяс ибн Мудар ибн Низар ибн Мад ибн Аднан ибн Адад ибн Мукаввим ибн Нахур ибн Тайрах ибн Иаруб ибн Яшджуб ибн Набит ибн Исмаил ибн Ибрахим ибн Азар (Тарих) ибн Нахур ибн Саруг ибн Шалих ибн Ирфхашад ибн Сам ибн Нух ибн Ламк ибн Матту Шалах ибн Ахнух (Идрис) ибн Иард ибн Махлил ибн Кайнан ибн Ианиш ибн Шис ибн Адам [16].

Указанные факты позволяют сделать выводы о том, что национальные деление людей условно и в действительности они родственники, братья и сестры, дети Адама, Нуха, Ибрагима, и обязаны жить мирно, дружно и помогать друг другу. Однако посредством дьявола воюют и убивают друг друга изза того, что мирно не могут разделить материальных благ. Поэтому в Исламе все члены уммы (сторонники) объявлены братьями. Велено им разделить результа-ты своих экономических действий справедливо и пропорционально в пределах потребности. Экономно использовать материальные дары. Постоянно совер-шенствовать духовным дарам: мировоззрению, рассудку, знанию, умственным и трудовым навыкам, способности, вести порядочный и обильный образ жизни. Ухаживать за развитием материальных дар (благ) природы и беречь их. За все достижения в материальном мире, духовной сфере и в обильном образе жизни помолиться (благодарить) Господу Богу.

Базируясь на здравой логике можно сказать, что Господ Бог, создал свою прекрасную природную среду и вселил в неё соответствующие существа - растений, животных и людей с равной степенью любви. Людей Он этнически, по классам и слоям не разделял. Всё было создано прекрасно. Наблюдаемые в этот мир все уродства являются результатами злых намерений и деяний людей и считаются размножением их неграмотности. Бог милосердный тем, кто сознает себе, своего Создателя, отвечает за свои деяния и выполняет обязанности точно.

Каждый грамотный мусульманин глубоко убежден в том, что Господ Бог, создав человеческие роды, заботился об их знание. Разным способом (откровение, послание через ангелов священные писания и книги, внедрение особенной способности рассуждения и пр.) своих любимцев (созданных): Адам и его сыновья в количестве 124 тысячи пророков и огромных групп ученых, поэтапно, снабдил знанием, обучил методам и способам развития, вооружил способностями и позволил присваивать необходимые достижения.

Достаточно факты, что пророк Мухаммед призвал свой уммат (сторон-ник) на правильный путь и велел им: «Постоянно реформируйте действия и образ жизни. При этом считайте, что никогда не умрете. Одновременно учтите, что завтра можете умереть»; «Каждому уммату (стороннику) необходимо: послушать науки, изучить их, применять на практике и распространять в обществе (среди молодых поколений)»; «У брата Мусы хорошо видел левый (внешняя, материальная) глаз, у брата Исы хорошо видел правый (внутренняя, духовная) глаз, а у меня оба глаза (и материальная и духовная) хорошо видят»; «Учёный - это свет общества, ее путеводитель, если он умрёт, значит, оно лишается этих достижений»; «Чернила ручки ученого весит больше, чем кровь погибшего в борьбе за правое дело» и пр.

Перед формированием Ислама арабское общество было нецивилизован-ным, невежественным, варварским и проявляло незначительный интерес в интеллектуальной сфере. Именно Коран сыграл важную роль в переломном изменении ситуации. Первое кораническое откровение призвало пророка Исла-ма искать знания, подчеркнув важность учения в жизни человека. Коран неоднократно призывает людей изучать и понимать силы природы с тем, чтобы использовать их на благо общества и для интеллектуального развития и, тем самым, Коран научил людей научному образу мышления. Коран ясно говорит о том, что все, что существует в небеcax и на земле, подчинено людям, которые являются наместниками Аллаха. Аллах одарил людей способностью исполь-зовать их интеллект, чтобы они размышляли о происходящем вокруг них и выражали свои мысли с помощью речи и письма. Му- 
сульмане через коранические призывы и слова пророка вдохновляются на поиски знаний, изучение природы с тем, чтобы увидеть в ней Творца, что в свою очередь способствует интел-лектуальному росту. Уместно было бы вспомнить о том, что ряд видных историков и научных исследователей, таких как Джон Виллиамс, Е. А. Майерс, Макс Меерхоф, Филип К. Хитти, Джордж Сартон, М. Улман, Е. Д. Браун, Сей-видж Смит и др., полностью признали роль, которую сыграли средневековые мусульманские учёные в сохранении знаний Древней Греции, Персии и Ин-дии, но также и их оригинальный вклад в сокровищницу знаний [2, стр. 99102].

Результативность, оригинальность и креативность науки и технологии в мусульманском мире сохранялись вплоть до шестнадцатого столетия. В тече-ние этого периода мусульманские учёные и исследовательские труды посте-пенно распространялись в Европе. Сицилия и Испания были основными мес-тами такого распространения. Из Испании знания распространились за пределы Пиренеев на западную и юго-западную часть Франции и Сицилии. Христиан-ский правитель Роджер II способствовал распространению мусульманских научных достижений и культуры на всей территории Италии и через Альпы, перенеся их влияние в различные европейские страны, которые превратились в арабские учебные центры...Благодаря щедрой поддержки научной деятельнос-ти со стороны испанских Омеядских халифов были созданы новые уникальные научные работы. «Мир держится на четырех стопах: мудрости ученых, справедливости великих личностей, молитвах праведных и мужестве храбрых», эту надпись часто можно было увидеть у входа в университеты Испании в период мусульманской эры [2, стр. 103-104].

Греческие учёные были прекрасными специалистами в разработке теорий и выдвижений гипотез. Они были выдающимися наблюдателями, но не экспе-риментаторами. В греческой литературе не встречаются документальные свиде-тельства об экспериментах. Мусульманские учёные, впервые в истории, пред-ставили концепцию фиксирования данных, основанных на наблюдении и экспе-рименте. Греки были твердо убеждены в том, что мнения Аристотеля и Платона являются окончательными и что в их взглядах не может быть ошибки, хотя они были известны как теоретики, пытающиеся объяснить различные феномены в меру своих способностей в области спекулятивных знаний. Об этом подробно писал Бриффолт: «Наука обязана в основном арабской культуре, она обязана своим существованием арабским ученым, которые сделали удивительные открытия и выдвинули революционные теории. Греки систематизировали, об-общали и теоретизировали, но терпеливые исследования, аккумуляция пози-тивных знаний, протоколирование научных данных, подобные, долгие наблюде-ния и принцип экспериментирования были представлены Европе арабами» [2, стр. 105-106].

Мусульмане развили текстильную, шелковую, хлопчатобумажную, кож-ную промышленности. В течение девятого и десятого веков, сотни кораблей из мусульманских стран стояли в портах Кантона и Китая. Мусульманские торговцы установили систему аккредитивов по типу чеков. Мусульмане занимались сельским хозяйством, применяли передовые научные методы и знали о полезности удобрения. В двенадцатом веке сельское хозяйство, орошение и производство сельскохозяйственного оборудования были намного более передовыми, нежели в немусульманской Европе. Эта передовая техно-логия позже была перенесена из Испании в Италию и Северную Европу. Как писал об этом Филип Хитт: «В начальный период средневековья ни один народ не сделал важного вклада в человеческую цивилизацию так, как это сделали арабы. С девятого по двенадцатый век, в области медицины, философии, истории, астрономии и географии на арабском языке было написано больше работ, нежели на любом другом языке» [2, стр. 117]. Такие объективные факты в источниках достаточно много, но ограничимся вышеуказанными фактами.

\section{2. Успехи экономических действий размноже- ния духовной зрелости}

Человеческое существо получило право свободы от своего Создателя. При этом его духовное развитие направляется Вождем. Степень духовного раз-вития определяет правильность его выбора и экономических действий, взаимо-отношений в общественный строй. Целенаправленно формируются его обязан-ности и задачи: следить за нормальном и гармоничном развитие элементов природы; обеспечить себя, своего рода всеми духовными и материальными ценностями; создать обильные, счастливые панорамы проживания. Современная экономическая система представляет собой очень сложную и комплексную структуру. Экономические принципы действий мусульман являются простыми, ясными и передовыми, они несут цель гармоничного социального развития, направленное на решение проблемы бедности и несправедливости.

Известно, что даже в странах, которые считаются самыми богатыми, технологически передовыми и имеют все средства в своем распоряжении для того, чтобы устранить болезни, бедности, порожденные своей экономикой и, однако, несмотря на это хронически страдают от этой болезней. Даже в таких обществах есть в значительном количестве голодающих и бездомных, наблюдаются нехватки медицинской помощи и несправедливости при распределении доходов и богатства, резкого несоответствия на фоне изобилия этих стран.

Исламисты экономическое процветание считают одним из необходимых условий для достижения научного прогресса. Для чего основываются на прин-ципы справедливой, экономичной экономики и процветание человека. Фунда-ментальный принцип исламского образа жизни - это не только религия, а комп-лексный образ жизни и экономические отношения являются составной частью целостной системы. Исламские исследователи эту систему рассматривают в трех составных частях: основной принцип утверждения и управления социаль-ной, 
экономической и политической системы и сравнение его с основными принципами современных систем; концепция экономического прогресса, с учетом разницы между ростом и развитием, их последствия для справедливости и процветания человека; фундаментальные черты исламской экономической системы и исследование их последствия. [2, стр. 122].

Фундаментальный принцип исламского образа жизни, как в любой другой системе, это социальная и политическая стабильность и экономическое процветание. Для реализации этой стратегии рассматриваются два альтернативных направления действий: привлечение к участию посредством применения силы или побуждение к добровольному участию путем завоевания сердца и умов людей. Исламская концепция развития основывается на второе направление действий, поэтому более плодотворно и приемлемо была, есть и будет.

Установление субъективной и комплексной правовой системы, примене-ние силовых методов для ее внедрения, сопровождаемое суровым наказанием за неподчинение, является характерной чертой силового привлечения к действиям, которые широко применяются в таких противоречивых системах как капитализм и коммунизм (социализм), доминирующие в современном мире идей и практики. Исламская система представляет собой альтернативную систему, которая функционирует и процветает при искреннем и добровольном участии членов общества.

Фундаментальное отличие между этими двумя направлениями развитие заключается в их философии, взглядах на человеческую жизнь и отношениях к ней. В капиталистических и социалистических обществах рассматриваются человеческая жизнь как субстанция, состоящая из тела и ума. Его душа совершенно не принимается во внимание, то есть её существование и роль остаётся непризнанной. Поскольку душа не имеет ценности в обществе, экономике и политике, люди, в целом, не уделяют ей внимания и в своей индивидуальной жизни. Члены такого общества устремлены только к обретению материальных благ, власти и получению удовольствий, не придерживаясь никаких нравственных принципов, либо придерживаясь их в незначительной степени и не уделяя внимания потребностям своей души. По причине отсутствия какого-либо высокого идеала, помимо стремления к материальным благам и власти, принцип Дарвина о выживании наиболее приспособленного становится единственным руководящим принципом для людей в их конкурентной погоне за материальным успехом в жизни [2, стр. 123].

Ислам обеспечивает социальную и политическую стабильность, достига-ет экономического процветания путем установления справедливой системы благодаря добровольному участию членов общества. И это достигается не путем устрашения силой закона, а путем воспитания членов общества. Ислам помогает людям развить в себе наилучшие человеческие качества. С этой целью религия воспринимает жизнь человека, в отличие от западного мышления, во взаимосвязи трех компонентов: тела, сознания и души. Всем им уделяется должное внимание в исламской философии и практических действиях, чтобы благополучно развивать личности с наилучшими качествами, целенаправленно функционировать в общественной системе. Исламская вера почти полностью устраняет необходимость правого мониторинга, поскольку члены общества не только являются добровольными и преданными участниками, но также осуществляют самоконтроль. Духовное возвышение личности человека подразумевает самоконтроль личности за своим поведением в соответствии с универсальными принципами нравственности, физическое и умственное развитие способствует свободному материальному прогрессу, которое ведет к развитию цивилизации, экономическому росту и формированию плодотворного интеллектуального капитала общества, о чем мечтают и сторонники постиндустриального общественного строя на современном этапе развития человечества.

Исламская экономическая система функционирует под воздействием рынка. Предоставляется частное право на использование ресурсов. Свободное частное предпринимательство находится в центре экономической системы, малым и средним предпринимателям дается преимущество, ибо они способ-ствуют зарождению инициативы и стимулы, содействуют инновациям, и дает высокую производительность. Не устанавливается предел тому, сколько человек может заработать и потратить, скорее, устанавливается жесткие ограничения на то, как человек зарабатывает и как тратит заработанное состояние. Запрещается риба (лихоимство) - заранее установленная фиксиро-ванная выплаты ссуды, независимо от того находится ли заемщик в прибыли или убытке. Поощряется продуктивное обращение дохода и материального богатства. Запрещается непродуктивная аккумуляция богатства и эксплуататор-ский метод накопления богатства. Также предметом запрета считаются удер-жание товаров с целью поднятия цен и азартные игры, производство и продаж наркотиков, действия, которые вредят здоровью и нравам людей.

Здесь уместно было бы подчеркнуть, что необходимость запрета рибы (займы, кредитные отношения по методам немусульманских сообществ) возникла из-за практики формирования рабовладельческого строя после разложения первобытных сообществ людей. Основоположники исламской культуры, руководствуя принципом справедливости, участия собственников капитала, на кооперативных началах, в производственных процессах путём получения доли с прибыли считали целесообразным.

Ислам требует самостоятельности и уверенности в своих силах от каж-дого члена общества и не одобряет зависимость от других. Уверенность в своих силах является превосходным качеством и поощряется. Таким образом, обеспе-чиваются условия, при которых каждый член получает равную возможность в приобретении дополнительных 
средств, необходимых им в работе. Первое и наиболее важное дополнительное средство это человеческий капитал, то есть знание. Ислам сделал приобретение этого средства обязательным для каждого мусульманина, как для мужчин, так и для женщин.

В Исламе борьба с бедностью занимает центральное звено действий. Ис-коренение бедности считается социальной ответственностью общества. Используются разные методы: уплачиваются закят (2,5\%-ый налог на подобии имущественного налога и налога с прибылей) и хумс (обязательный налог, составляющий одну пятую от годового дохода) и фитра (уплачивается бедным по завершению месяца рамазан), выдаются назир (приношение святым местам и раздача бедным), садага (оказание материальной и денежной помощи бедным) и кур бан (жертвоприношение мелкого и крупного скота, с условием раздачи бедным). Существование бедности в обществе считается ужасным грехом для всего общества. Самым серьезным грехом в исламе является неверие, что означает отрицание власти Бога. Исламская экономическая систе-ма сочетает в себе полезные черты капиталистической и коммунистической системы, однако, она лишена отрицательных черт, присущих им. Применение свободного предпринимательства и рыночных механизмов наряду с приме-нением эгалитарных принципов обеспечивает условия, при которых система становится эффективной и справедливой. Отсутствие права владения ресурсами и неограниченной власти при использовании этих ресурсов, как со стороны отдельных индивидуумов, так и со стороны государства, освобождает общество от тирании в их использовании и владения. В этом смысле, исламская система представляет собой умеренный средний путь - умеренную систему, предна-значенную на благо человечества [2, стр. 133].

Справедливая форма исламских вкладов на основе принципа участия в прибылях и убытках делает их отличными от обычных депозитов в традиционных банковских услуг. Финансовые возможности исламских предпри-нимателей укрепляются и стабилизируются потому, что основываются на двенадцати принципах учета и аудита, строго предусматривают пись-менные разъяснения и прозрачность балансовых и финансовых отчетов.

С 1150 года современной эры до шестнадцатого столетия иудейские, христианские и мусульманские учёные из Западной Европы и Испании зани-мались переводом книг с арабского на латинский язык в Академии Толедо, ос-нованной Альфонсо и Сабио Мудрым. Эти переводы распространялись в ака-демические центры Европы, они послужили основой Ренессансу, возрождению знаний в Европе [2, стр. 153]. Многочисленные исследователи поставили перед собой цель, чтобы устранить философский разрыв, который ныне разделяет Восток и Запад, большой вклад внесли в ее реализацию.

Именно Ислам дал миру методы институционализации, методы практи-ческого применения благоприятных принципов моногенетического ра- венства, человеческого достоинства, справедливости, толерантности, совести и дисцип-линированной свободы человека. Прежде всего, он придал целостность челове-ческой натуре, основанной на высоком духовном чувстве ответственности человека за свои поступки, как наилучшим образом обращаться с другими людьми, с флорой и фауной и с природными ресурсами. Эти божественные благодеяния должны быть использованы на благо всего человечества без каких-либо легкомысленных расточительств.

Благодаря применению этих принципов, мусульмане восстановили духов-ные ценности, изменили социальное, экономическое и политическое устрой-ство, преобразив жизнь человека к лучшему на все времена. Это освободило людей от предубеждений, основанных на различиях пола, расы, рода, вероиспо-ведания или национального происхождения и позволило признать праведность и ответственность в поисках человека в качестве единственных критериев для определения его превосходства или более низкого положения. Ислам подчеркнул роль семьи в формировании личности человека от младенческого возраста и даже в течение предродового периода.

Добродетельные и нравственные законы создают великие общественные институты, которые, в свою очередь, порождают выдающиеся личности, кото-рые начинают предпочитать и распространять добродетель в качестве критерия своей коллективной культуры. Роуз У. Лэйн, рассказывая о влиянии образа жизни мусульман на европейцев, писал: «Крестоносцы, вернувшиеся в Европу, впервые принесли к себе в родные края понятие о благонравном человеке. До вторжения на земли Сарацинской (непочтительный термин, применяемый ими в отношении к жителям Сирии и в том числе к мусульманам и арабам) цивилизации, они не имели представления о том, что сильному человеку не обязательно быть грубым и жестоким. Сарацины были прекрасными воинами в сражениях, но они не были жестоки, они не подвергали мукам своих пленных, они не убивали раненных. В своей стране они не подвергали христиан преследованиям. Они были смелыми людьми и в то же время были деликатными и мягкими. Они были великодушными, правдивыми и выполняли свои обещания» [2, стр. 162]. Эти исламские черты впервые поразили образованных итальянцев, которые были первыми европейцами, которые вступили в контакт ближневосточными мусульманами. Британцы старались перенять эти черты. Об этом как писал Лэйн: «Он (Ислам) все еще продолжает создавать, возможно, наилучших представителей рода человеческого на земле сегодня, мужчины и женщины правящего класса Британии. Он представляет собой идеал, который проникает во все сферы американской жизни. Из таких общих и смутных упоминаний американец может получить представление о людях, с которыми имели дело итальянцы до и во время пробуждения Европы...» [2, стр. 162].

Аспекты нравственности присутствовали во всех видах деятельности му-сульман - в духовных, 
социальных, экономических и политических сферах. Члены всех немусульманских меньшинств были освобождены от военной службы, находились под защитой мусульманского большинства. На мусульман возлагались обязанность защищать жизни представителей немусульманских меньшинств, охранять их земли и оберегать их свободы. Образование на всех уровнях было доступным для всех независимо от пола, расы, рода или социально-экономического статуса. У рабов также были просторные возможности возвыситься до уровня сана правителя [2, стр. 163].

Отрадно, что в настоящее время в сферу, как научных исследований, так и обсуждений включена такая важная проблема как философия диалога, решением которого заинтересованы политики, социологи, философы и все слои интеллигенции.

Именно по инициативу руководителей Азербайджанской Республики уже регулярно, в формате межкультурального, межцивилизационного и межрелигиозного диалога, проводится международные конференции, семинары, научные симпозиумы и прочие экономические, культурно-гуманитарные мероприятия, посвященные вопросам: гуманитарность, религиозная терпимость, диалог и мультикультурализм. В этих мероприятиях участвуют знатные личности, ученые и компонентные специалисты многих стран мира. Их проведение превратилось в традиционный случай. По выражению Президента Ильхама Алиева «... проводимые разные международные конференции вносят великолепный дар в развитие межрелигиозного диалога...». [8, стр. 247] В результате проведения целенаправленных мероприятий, нужно сказать, что Азербайджан превратился в центр толерантности мира и успешно распространяет свои практики в другие страны.

Мудрость философии диалога заключается в том, что оно подавливает страсть находившийся в состоянии взрыва, налаживает противоречия общества, является формой мышления, позволяющее оптимальному решению вопросов по успокаиванию войск, ожидающие приказ о нападении, клики тех, кто делает призыв: «война, война», по сужению нервы тех, которые пренебрежительно относятся к людям, обществу и детским плачам, игнорируют подходы к страданиям людей [9, стр.9].

По рассуждениям философов Азербайджана «человечество может преодолеть свои проблемы только путём совместного сотрудничества религий, философии и науки» [9, стр.158]. Они считают, что «диалог и сотрудничество между религий всегда должно считаться как важной составной частью диалога и сотрудничества между цивилизации» [9, стр. 173].

Уместно было бы вспомнить, что народные мудрецы всегда советуют: религия питает дух, наука совершенствует мозг (ум), а занятость (труд) успокаивает сердце, когда они действуют сообща во взаимодействии, цель и эффективность превращается в реальность.
В этой статье мы коротко характеризовали некоторые преимущества Ислама. Старались довести научной общественность её истинную сущность, прогрессивность и инновационное качество, которое неизбежно в формировании здравомыслящих, плодотворных и полноценных членов (индивидов) глобального сообщества человечества, в основе которого должна лежать достоверная информация, полезные научно-консультативные услуги и технологические развития.

\section{3. Заключение}

Проводимая, начиная с шестнадцатого века, реформа в Европе носила в себя предпочтение материальному развитию, а духовному развитию дано не-должное внимание. Результаты такого подхода можно характеризовать следующими неполноценными явлениями и тезисами: во-первых, не обеспечена комплектность и равновесие, нарушено действие объективного закона гармонизации; во-вторых, способствовало формированию таких неверных рассуждений как не совместимость религии с наукой и с государством, о происхождении человека, варварское отношение к накоплению капитала и зажиточности. Опасные и страшные последствия, которые проявились за короткое время примерно в течение пяти веков: формирование мировоззрения о приближении конца мира; истощение природных ресурсов; разжигание войн и невиданные в истории человечества кровопролития и терроризм; формирование у молодого поколения такого нежелательного характера как лживость, лицемерие, нетерпимость к религиозной разновидности; сбивание с пути владения объективным знанием, плодотворной способность и занятия полезной трудовой деятельности и направление молодежи в сторону разгул (оргия), который постепенно охватывает широкие их слои. Такой подход неприемлем для всей территории и наций мира, которые формировали глобальную систему экономических отношений и взаимодействий, он может быть подходящей только европейской среде. Это явный путь разрушения человечества и ее цивилизации, от которого не могут спастись ни богачи и ни бедные.

Одностороннее развитие мировоззрения индивидуумов обществ размножает неполноценное общественное сознание, снижает плодотворности труда, превращается в тормозящие силы интеллектуального, экономического и социального развития общества.

Путь спасения от ожидаемой опасности пролежит в формировании миро-воззрения у всех наций и народности способ воспитания и обучения, основан-ный на развитии во взаимодействии трех компонентов - тела, сознания и души человека. Для этого необходимо развитие духовной, экономической, социаль-ной и общественной концепции с учётом прогрессивных подходов всех дей-ствующих религий, в том числе, иудаизма, христианства и ислама. Следует развивать науки и технические достижения без корыстных намерений и целей, по принципам справедливости и ради служения всем 
нациям и народностям. Научные и технические достижения несовместимы с национальными разделами, не имеют ограниченную сферу действия. Все достижения и в прошлом и в настоящем времени подлежат служению всему человечеству. Это есть стержень формирования постиндустриального этапа общности людей.

\section{Список литературы / References}

1. Коран - толкование, на азербайджанском языке. Перевод под руководства Зия Бунядова и Васима Маммедалиева. Баку, 1992, 710 стр.

2. Башир Ахмед М., Саид А. Ахсани, Дилнаваз А. Сиддикуи. Вклад мусульман в мировую цивилизацию, Международный Институт Исламской Мысли P.O. Box 126,Richmond, Surrey TW9 2UD, UK. Главный офис Р.О. Вох 669, Herndon, VA 22070, USA. Общественное Объединение «Идрак», Баку, 2008, 180 стр.

3. Хаджа Насираддин Туси. Ахлаги Насири (Этика Насира). Баку, 2005, 256 с. (на азербайджанском языке).

4. Муртаза Мутаххари. Основные причины направленности к материализму. 1992, 204 с. (на азербайджанском языке).

5. Сейид Нашим Расул Мехаллати. Жизни пророков. 2005, 608 с. (на азербайджанском языке).

6. Ахмедов А. А. Аргументы Бога. Баку, 2009, 302 с. (на азербайджанском языке).

7. Музниб Алаббас. Краткая история пророков и Ислама. Баку, 1990, 60 с. (на азербайджанском языке).
8. Алиев И. Г. Азербайджан пример толерантности (выступления, речи, встречи, поздравлении), Баку, 2015, 265 стр.

9. Зейналов Ш. А. Философия диалога. Баку, изд. «Европа» 2017, 304 с

10. Зейналлы А.Т. Основные принципы формирования потребительского рынка современного экономического отношения // XLV international correspondence scientific and practical conference «International scientific review of the problems and prospects of modern science and education» (Boston. USA. May 24-25, 2018). С. 46-53.

11. Зейналлы А.Т. Основные показатели, характеризующие системы экономического механизма и методология их подсчёта // European Journal of Economics and Management Sciences. Austria. Vienna, 2017. № 3. Стр. 67-103.

\section{Электронные ресурсы}

12 Режим доступа: https://d1.islamhouse.com/data/ru/ih/история авраама . (дата обращения: 17. 01.2019)

13. Режим доступа: https:/ ru.wikipedia.org/wiki/Моисей (дата обращения: 17 . 01.2019)

14. Режим доступа: https://fb.ru/article/310399/iisus-v-islame-prorok-isa-ibn-maryam.

(дата обращения: 17. 01.2019)

15. Режим доступа: https:// ru.wikipedia.org/wiki/Мухаммед (дата обращения: 17. 01.2019)

\title{
РОЛЬ НРАВСТВЕННОЙ КУЛЬТУРЫ ЛИЧНОСТИ
}

\author{
Мамадиева Нилуфар Халиловна \\ кафедра «Философия и наџиональная идея» \\ Узбекистан, ТашГТУ.
}

В этой статье рассматривается структура и анализ элементов нравственной культуры человека. В системе конкретно данной нравственной культуры формируются нравственные идеалы, ценности ориентации, нравственные чувства, нравственные убеждения.

Нравственная культура - это понятие, характеризующее процесс осознания к усвоения членами общества устойчивых моральных норм, принципов идеалов и т.д. превращения их в убеждения, в правила личностных поступков в практическую деятельность. Следовательно, нравственная культура - это критерий нравственное развития общества, социальных групп, индивидов и т.п.

Нравственнность после того, как уходит в прошлое миф, где человек внуреннние сливался с жизнью коллектива и контролировалс различными магическими табупрограммировавшими его поведение на уровне бессознательного. Теперь человеку требуетсясамаконтроль в условиях относительной внутренной автономности от коллектива. Так возникают первые нравственные регулятивные - долг, стыд и чест[1.с.18].

Нравственность или мораль, будучи своеобразным продуктом духовной деятельности людей, рассматривает общественныме отношения, поступки людей социальные факты и события через призму свойственных ей понятий добра и эта долга и чести, справедливости и др. Нравственные оценки, опирающиеся на эти понятия выражают характер поведения людей и их взаимоотнощения. Мораль включает в себе на определенную савокупность идей, взглядов, принципов, реализумых в процессе деятельности, так и нравсьтвенные качества людей, чувства, привычку и т.д.

C повищением внутренней автономности человека и формированием зрелой личности возникает такой нравственный регулятив, как совесть. Таким образом, нравственность появляется как внутренняя саморегуляция в сфере свободы, и нравственные требования к человеку растут по мере расширения этой сферы.

Развитая нравственность есть реализация духовной свободы человека, она основано на утверждении самоценности человека независимо 